\title{
REVIEW
}

\section{Year in review 2011: Critical Care - respirology}

Jesús Villar*1-3, Haibo Zhang ${ }^{3,4}$, Jesús Blanco ${ }^{1,5}$ and Arthur S Slutsky,4

\begin{abstract}
Management of acute respiratory failure is an important component of intensive care. In this review, we analyze 21 original research articles published last year in Critical Care in the field of respiratory and critical care medicine. The articles are summarized according to the following topic categories: acute respiratory distress syndrome, mechanical ventilation, adjunctive therapies, and pneumonia.
\end{abstract}

\section{Introduction}

This review article summarizes 21 original research papers published last year in Critical Care in the field of respiratory and critical care medicine. For the sake of a more focused discussion, these articles are grouped into four categories: pathogenesis of the acute respiratory distress syndrome (ARDS), mechanical ventilation, adjunctive therapies, and pneumonia.

\section{Pathogenesis of acute respiratory distress syndrome Damage-associated DNA and microparticles \\ Cell-free DNA is detected in blood in many diseases and can originate from necrotic cells or apoptotic processes to reflect the extent of cellular damage. ARDS is asso- ciated with several acute diseases that may cause cell death and release of DNA into the bloodstream [1]. Okkonen and colleagues [2] performed a multicenter study to measure the plasma levels of cell-free DNA and to evaluate their prognostic indication in 580 mecha- nically ventilated patients with ARDS, as defined by the criteria of the American-European Consensus Confer- ence [3], included in the FINNALI study [4]. The authors found that plasma concentration of cell-free DNA at baseline was an independent predictor of 90-day mortality. However, the study did not find a correlation}

*Correspondence: jesus.villar54@gmail.com

'Multidisciplinary Organ Dysfunction Evaluation Research Network, Research Unit, Hospital Universitario Dr. Negrin, Barranco de la Ballena s/n, 4th floor South wing, 35010 Las Palmas de Gran Canaria, Spain

Full list of author information is available at the end of the article between the plasma cell-free DNA concentration at admission and baseline tidal volume (VT) normalized to predicted body weight. There were no statistically significantly differences in plasma cell-free DNA concentrations between patients with ARDS and those without it. Therefore, the usefulness of plasma cell-free DNA concentration as a predictor of mortality may be limited in the heterogeneous group of mechanically ventilated patients, probably because of confounding effects of comorbidities among other factors [5].

The local and systemic inflammatory responses in ARDS are orchestrated by the interaction between circulating cells such as leukocytes and platelets and endothelial cells. During inflammatory responses, these cells release microparticles that have proven to be sensitive markers for assessing the activation/apoptotic status of cells in many inflammatory disorders such as sepsis and trauma [6]. Microparticles bound on plasma membrane are negatively charged phospholipids. Guervilly and colleagues [7] measured the concentrations of microparticles isolated from bronchoalveolar lavage fluid and blood in 52 patients with ARDS within the first 72 hours of ARDS diagnosis. Since poor outcome in critically ill patients is associated with endogenous immunosupression [8], the authors hypothesized that high levels of microparticles from leukocytes may be associated with better outcome. They found that microparticles that originated from platelets, endothelial cells, and leukocytes were detectable in the bronchoalveolar lavage fluid and that higher levels of circulating microparticles from leukocytes at the time of ARDS diagnosis were associated with better prognosis. This observation is in agreement with previous findings in patients with severe sepsis [9]. The study of Guervilly and colleagues [7] suggests that measurement of microparticles may be considered a biomarker of prognostic significance in ARDS. Further studies are required to validate the findings.

\section{Airway remodeling}

High inspiratory lung volumes or pressures during mechanical ventilation can cause injury through alveolar overdistension in patients with acute lung injury. Recent studies suggest a role for distal airway epithelium injury in the pathophysiology of mechanically ventilated patients with ARDS [10]. Airway morphological changes 
have been reported in experimental models of ARDS and are characterized by epithelial necrosis and denudation in distal airways. Morales and colleagues [11] evaluated, for the first time, the structural and inflammatory changes in small distal airways in lung tissue from 31 patients who died of ARDS. Lung tissue from 11 patients who died of non-pulmonary causes served as controls. The authors found that ARDS airways had a shorter extension of normal epithelium and a larger extension of epithelium denudation, which was negatively correlated with the arterial partial pressure of oxygen/fraction of inspired oxygen $\left(\mathrm{PaO}_{2} / \mathrm{FiO}_{2}\right)$ ratio. There were also increased airway inflammation, higher airway wall thickness, and higher airway content of collagen, fibronectin, and matrix metalloproteinase-9 in comparison with controls.

\section{Mechanical ventilation \\ Brain-lung interactions}

Most patients with ARDS die of multiple organ dysfunction rather than hypoxia [12]. Injuries to the brain and lung are frequent causes of admission to intensive care units (ICUs) and are associated with high morbidity and mortality rates [13]. In addition, many critically ill patients who undergo long-term mechanical ventilation have neurological impairment [14]. Survivors from ARDS frequently have some cognitive deterioration at hospital discharge. The underlying inflammatory responses or biotrauma induced by the use of mechanical ventilation or both may be responsible for distal organ dysfunction. Quilez and colleagues [15] examined the impact of ventilator-induced lung injury on the brain in rats. Healthy rats were ventilated for 3 hours at a VT of 8 and $30 \mathrm{~mL} / \mathrm{kg}$. The investigators demonstrated a significant increase in immune cells expressing $c$-fos in the retrosplenial cortex and thalamus in animals ventilated at high VT but not in the low-VT and unventilated groups. That study suggested that mechanical ventilation per se promotes a brain inflammatory response similar to that seen in the lung.

\section{Positive end-expiratory pressure titration}

Lung protective ventilator strategies minimizing tidal volume and plateau pressure have been shown to improve survival in patients with ARDS [16-18]. Clinicians use high positive end-expiratory pressure (PEEP) to improve alveolar recruitment in patients with ARDS, although the best strategy to set optimal PEEP has not yet been established. A previous study suggested that the measurement of the respiratory system reactance provides a more reliable readout than the dynamic compliance in assessing the degree of lung collapse and the effectiveness of recruitment maneuvers [19]. Kostic and colleagues [20] evaluated the use of respiratory system reactance to identify the minimal PEEP level required to maintain lung recruitment in a porcine model of ARDS induced by saline lavage. Multiple PEEP levels were titrated on the basis of the respiratory system reactance measured by forced oscillations or were set according to the ARDSNet protocol [16]. The investigators found that the mean PEEP levels set on the basis of the respiratory system reactance were significantly higher than those based on the ARDSNet approach. The higher PEEP levels were associated with improved lung mechanics, reduced driving pressure, greater oxygenation, and lower lung injury scores. That study suggests that repeated assessment of PEEP optimization could improve lung mechanics and reduce ventilator-induced lung injury. Whether the respiratory system reactance could be an important component for delivering protective mechanical ventilation in ARDS will require further studies.

It is unclear whether lung recruitment maneuvers add any benefit to low-VT protective ventilation strategies in ARDS [21]. In a small randomized controlled trial, Hodgson and colleagues [22] examined the effectiveness and safety of a novel open lung strategy in 20 patients with ARDS. The approach consisted of permissive hypercapnia, application of staircase recruitment maneuvers, and low airway pressure with PEEP titration early in the course of ARDS (ventilated for less than 72 hours). Patients in the control group were ventilated according to the ARDSNet protocol [16]. For the staircase maneuver, the high pressure was set $15 \mathrm{~cm} \mathrm{H}_{2} \mathrm{O}$ above the PEEP, which was increased in a stepwise manner to 20 , then 30 , and then $40 \mathrm{~cm} \mathrm{H}_{2} \mathrm{O}$ every 2 minutes and then reduced to 25 , then 22.5 , then 20 , then 17.5 , or then an absolute minimum of $15 \mathrm{~cm} \mathrm{H}_{2} \mathrm{O}$ every 3 minutes until a decrease in saturation of oxygen in arterial blood $\left(\mathrm{SaO}_{2}\right)$ of greater than $1 \%$ from a maximum $\mathrm{SaO}_{2}$ was observed. This was defined as the derecruitment point. PEEP was then increased to $40 \mathrm{~cm} \mathrm{H} \mathrm{O}$ for 1 minute and returned to a PEEP level $2.5 \mathrm{~cm} \mathrm{H}_{2} \mathrm{O}$ above the derecruitment point. Hypercapnia was tolerated and acidosis was treated only if the $\mathrm{pH}$ was less than 7.15 by increasing the respiratory rate to a maximum of 38 breaths per minute. Patients received one recruitment maneuver until they were deemed to be ready for weaning. The use of this open lung approach resulted in a significant decrease in the levels of inflammatory cytokines in blood and improvements of oxygenation and lung compliance over a 7-day period, although there were no significant differences in duration of mechanical ventilation and ICU stay. Owing to the nature of the study design, it is unclear whether these physiological improvements would translate into clinically meaningful outcomes. However, in that study, the use of rescue therapies for hypoxemia was required in the control group only. 
Further investigation is required in a larger randomized trial.

To evaluate the effectiveness of PEEP on lung opening, lung ultrasound (sonography) was recently suggested for detecting aeration of lung regions [23]. The major advantages of this technique include avoidance of high radiation and the feasibility of bedside application. Stefanidis and colleagues [24] examined the feasibility of using the sonographic technique to detect changes of non-aerated lung regions in real time during a PEEP trial. In their study of 10 patients with ARDS, lung ultrasound was performed by a specialist blinded to the PEEP levels applied. The investigators demonstrated a significant $\mathrm{PaO}_{2} / \mathrm{FiO}_{2}$ ratio increase associated with a decrease in non-aerated lung areas when PEEP increased from 5 to $15 \mathrm{~cm} \mathrm{H}_{2} \mathrm{O}$. That study suggested that the lung ultrasound technique may be an alternative tool at the bedside for evaluating lung aeration in patients with ARDS.

Computed tomography $(\mathrm{CT})$ is considered the gold standard to evaluate regional lung aeration, but there is concern about radiation doses. Reske and colleagues [25] assessed total lung weight by using quantitative $\mathrm{CT}$ in 78 mechanically ventilated trauma patients who developed acute lung injury. A group of 74 trauma patients with normal lungs served as controls. The authors calculated the total lung volume, the total lung mass, and the masses of differently aerated lung compartments by using customized software as previously described [26]. The median value of total lung mass was greater in patients with acute lung injury. However, 59\% of them had CT values below the upper limit of the control level, suggesting that they most likely had atelectasis. In only $22 \%$ of patients, total lung mass was increased to the range previously reported for patients with acute lung injury and comparable to lung consolidation. Therefore, that study suggests that atelectasis is the most likely cause of lung dysfunction in more than half of patients who fulfill clinical criteria for acute lung injury after trauma. Whether quantitative CT could be helpful in identifying patients who could benefit from lung protective ventilation or surgical techniques remains to be studied.

In ARDS, functional residual capacity (FRC) is markedly decreased as a result of numerous factors, such as alveolar collapse, pulmonary edema, supine position, and sedation-induced diaphragm dysfunction [27]. The measurement of FRC or end-expiratory lung volume during PEEP might help to determine the aerated lung available for ventilation and for evaluation of the effectiveness of mechanical ventilation. Dellamonica and colleagues [28] assessed the precision of end-expiratory lung volume measurements at two different levels of PEEP by using the nitrogen wash-out/wash-in technique [29] in 31 patients with ARDS. The authors compared the changes with those measured with passive spirometry. In general, the new technique had good reproducibility and accuracy. Discrepancies occurred in four patients, all of them with the highest-set PEEP levels $\left(>16 \mathrm{~cm} \mathrm{H}_{2} \mathrm{O}\right)$. It is very possible, though not proven, that microleaks due to the high-set PEEP and the higher-set $\mathrm{FiO}_{2}$ values may explain these discrepancies in these patients. Repeated measurements may be required to check this discrepancy.

\section{Mechanical ventilation and body mass index}

Mechanical ventilation is the most important tool of life support for patients with ARDS. Across species, mammals have a resting tidal volume of about $6.3 \mathrm{~mL} / \mathrm{kg}$ ideal (or predicted) body weight $[30,31]$. The low-VT trial of the ARDS Network [16], supported by a long list of preclinical and clinical studies, unequivocally established that mechanical ventilation with large VTs can be injurious to the lungs. However, since the size of the recruitable lung in patients with ARDS is decreased [32], it is possible that the patients with severe ARDS in the ARDS Network trial were ventilated with a disproportionately larger VT than those with mild ARDS. Mattingley and colleagues [33] conducted an observational study in 14 patients to examine whether scaling VT to the size of the injured lung is safer and more physiological than scaling to predicted body weight. The authors found that there was a good correlation between the inflation maneuver-derived total lung capacity and the thoracic gas volume at end-expiration. When the body mass index was taken into account, this correlation was further strengthened, suggesting that setting mechanical ventilation on the basis of effective total lung capacity may be beneficial at the bedside. Han and colleagues [34] showed, in a cohort of 421 patients with severe sepsis-induced ARDS, that short people are less likely to receive lung protective ventilation. Since, aside from being shorter, women had characteristics similar to those of men, the VT calculated on the basis of predicted body weight and derived from height and gender would be smaller in women than men. Women were $40 \%$ less likely than men to receive lung protective ventilation during the first days of the onset of acute lung injury.

\section{Patient-ventilator dyssynchrony and ventilation distribution}

Patient-ventilator synchrony is important for effective ventilatory assistance. Patient-ventilator asynchrony is associated with prolonged mechanical ventilation and may lead to poor outcome [35]. Although it is a useful research tool, the calculation of an asynchrony index is time-consuming and does not provide real-time monitoring in mechanically ventilated patients. Gutierrez and colleagues [36] examined, in 110 mechanically ventilated patients, the efficacy of a new method for the detection of patient-ventilator asynchrony. The method is based on airflow spectral analysis that is characterized not by 
synchronous breaths but by a less organized spectral pattern. When this method was compared with the visual assessment of asynchronies from airway pressure and flow waveforms, sensitivity and specificity both exceeded $80 \%$. Since the method is non-invasive, fully automatic, and adaptable to existing ventilator systems, it may provide real-time information regarding patient-ventilator synchrony status during both invasive and noninvasive ventilation. Further evaluation is necessary to clarify whether such an approach would fit modes of ventilation that allow high breath-to-breath variability [37].

Measurement of ventilation and perfusion remains a complex task. It has been assumed that ventilation distributes preferentially toward the dependent lung and this is attributed to gravity [38]. Electrical impedance tomography (EIT) is a technique that has been shown to be able to distinguish both ventilation and perfusion. Grant and colleagues [39] used EIT in 10 healthy adult volunteers during spontaneous breathing in the supine, prone, and left and right lateral positions. The authors found a lack of gravity dependency of ventilation distribution in the supine/prone positions, and the two profiles were virtually identical. Gravity dependency was seen only in the lateral positions, and ventilation was greater in the left lung in the left lateral position, suggesting gravity-based shifts in anatomical structures. Anatomically, there was very little change in the chest from prone to supine positions, as evidenced by the similarity in the profiles. However, large changes in anatomy occurred with the shift of gravity direction when changing lateral positions. As the heart is in the left side of the chest, its impact on ventilation in the left lateral position is minimized. Ventilation distribution is compromised in the right lateral position as gravity causes a shift in the position of mediastinal organs.

\section{Liberation from mechanical ventilation}

The annual increase in long-term mechanical ventilation is five times the annual growth of hospital admissions [40]. In addition, many of these patients experience weaning failure. An imbalance between the muscular workload necessary to generate the required inspiratory pressure and the maximal pressure-generating capacity has been implicated as a major contributor [41] to this failure. Martin and colleagues [42] performed a randomized controlled trial to test whether inspiratory muscle strength training would improve weaning in 69 patients. The authors found that $71 \%$ of patients who received inspiratory muscle strength training were successfully weaned in comparison with $47 \%$ in the control group. Post-training maximal inspiratory pressure was independently associated with weaning success, suggesting that respiratory muscle weakness rather than fatigue is a greater contributor to weaning failure. However, the findings of this 'pilot' trial may not be generalizable since the sample size was small and the patients were primarily from a surgical ICU. Nevertheless, the study implies that a rehabilitation program to improve inspiratory muscle strength may be beneficial in the weaning process.

\section{Bronchi biotrauma}

Excessive alveolar inflation leads to upregulation of genes encoding inflammatory mediators leading to biotrauma [43]. However, the effects of mechanical stretch on basal tone and inflammatory responses of human bronchi are unknown. Faisy and colleagues [44] examined the effects of mechanical stretch in isolated human bronchi obtained from 48 patients undergoing thoracic surgery. After experimental preparation, bronchial rings were stretched for 5 minutes by using a force that corresponded to an airway inflation pressure of $30 \mathrm{~cm} \mathrm{H}_{2} \mathrm{O}$. The authors found that this force was able to induce epithelial leukotriene release and activation of several signaling pathways involved in lung inflammation and fibrosis. From a clinical perspective, the biological response of human airway to mechanical stretch emphasizes the impact of excessive lung inflation, especially in long-term mechanically ventilated patients.

\section{Adjunctive therapies \\ Prone and upright positions}

The prone position improves oxygenation in about two thirds of patients with ARDS [45]. A supine semirecumbent position has also been reported to improve gas exchange in patients with ARDS [46]. Robak and colleagues [47] evaluated the short-term effects of combining prone and additional upright positions in 20 patients with ARDS. The investigators randomly assigned patients to the prone position or combined prone with additional upright position (achieved by raising the head end and lowering the foot end of the bed) from an initial supine position. After 2 hours, the position was switched for 6 hours. The authors found that combining the prone with the upright position led to a further improvement in oxygenation, as assessed by changes in $\mathrm{PaO}_{2} / \mathrm{FiO}_{2}$. Considering these findings, the authors recommended that the combination of the two positions could be attempted routinely when clinicians are deciding whether to turn a patient with ARDS to a prone position.

Abroug and colleagues [48] updated a meta-analysis to examine whether the prone position in comparison with the supine position improves ARDS outcome. The authors analyzed seven randomized controlled trials, including 1,675 patients with acute lung injury/ARDS, of whom 862 were ventilated in the prone position. In general, the effects of prone positioning differed because 
of several factors, including the types and designs of the trials, and failed to exhibit an impact on mortality, mainly because the studies included patients with a wide spectrum of lung severity, different duration of prone positioning, and underpowered sample sizes. However, when just the four most recent trials that included only patients with ARDS were considered, the meta-analysis showed that prone ventilation was associated with a significant reduction of ICU mortality. This conclusion was contrary to what Sud and colleagues [49] reported in their first meta-analysis. However, in a second metaanalysis considering only ARDS patients with a $\mathrm{PaO}_{2} /$ $\mathrm{FiO}_{2}$ of less than $100 \mathrm{~mm} \mathrm{Hg}$, the same authors found that prone ventilation reduced all-cause mortality [50].

Rival and colleagues [51] proposed that a ventilation strategy combining prone position with recruitment maneuvers in early ARDS is a better approach for improving oxygenation. In 16 patients with early ARDS and severe hypoxemia $\left(\mathrm{PaO}_{2} / \mathrm{FiO}_{2}\right.$ of $\left.98 \pm 28 \mathrm{~mm} \mathrm{Hg}\right)$ requiring moderate to high levels of PEEP $\left(11 \pm 3 \mathrm{~cm} \mathrm{H}_{2} \mathrm{O}\right)$, the authors evaluated the effects of an extended sigh at $45 \mathrm{~cm} \mathrm{H}_{2} \mathrm{O}$ in a pressure control mode while patients were supine. The authors then repeated the same maneuver 1 hour after turning the patient to the prone position and at the end of 6 hours and found that improvements in $\mathrm{PaO}_{2} / \mathrm{FiO}_{2}$ ratio were transient in the supine position but lasted the longest during prone ventilation. Plateau pressures decreased after each recruitment maneuver over the entire prone ventilation period. This work showing that benefit from recruitment maneuver is better in the prone position confirms earlier experimental [52] and clinical [53-55] studies. Charron and colleagues [56] suggested that arterial partial pressure of carbon dioxide $\left(\mathrm{PaCO}_{2}\right)$ and alveolar dead space (VD/VT) are more relevant than $\mathrm{PaO}_{2} / \mathrm{FiO}_{2}$ ratio in monitoring the respiratory response to prone position in patients with ARDS, as first postulated by Gattinoni and colleagues [57], and performed a pilot physiological study in 13 patients with severe ARDS $\left(\mathrm{PaO}_{2} / \mathrm{FiO}_{2}\right.$ of less than $100 \mathrm{~mm} \mathrm{Hg}$ ). Responders to prone ventilation were defined after 15 hours of prone position either by $\mathrm{PaO}_{2} /$ $\mathrm{FiO}_{2}$ increase of more than $20 \mathrm{~mm} \mathrm{Hg}$ or by a $\mathrm{PaCO}_{2}$ decrease of more than $2 \mathrm{~mm} \mathrm{Hg}$. The authors also compared the measured and estimated VD/VT ratios in all time points by using a new method for estimation of the physiological dead space without measurement of expired $\mathrm{CO}_{2}$ [58]. Prone position induced decreases in $\mathrm{PaCO}_{2}$ and VD/VT and increases in $\mathrm{PaO}_{2}$. When the response to prone ventilation was defined by changes in $\mathrm{PaO}_{2} / \mathrm{FiO}_{2}$ ratio, no significant differences in plateau pressures, $\mathrm{PaCO}_{2}$, or VD/VT changes were observed between responders and non-responders. When the response was defined by $\mathrm{PaCO}_{2}$, responders $(n=7)$ had greater decreases in $\mathrm{VD} / \mathrm{VT}$ and plateau pressure and greater increases in $\mathrm{PaO}_{2} / \mathrm{FiO}_{2}$ ratio and respiratory compliance than non-responders $(\mathrm{n}=6)$. In summary, that study revealed that prone ventilation induced $\mathrm{PaCO}_{2}$ and VD decreases related to an improvement in respiratory mechanics. Testing the response to the prone position in ARDS appeared to be physiologically more relevant using $\mathrm{PaCO}_{2}$ changes than $\mathrm{PaO}_{2} / \mathrm{FiO}_{2}$ changes.

\section{Early manual hyperinflation}

Alterations in lung mechanics and reduction in pulmonary compliance are frequently implicated in postsurgical cardiac patients [59], and most patients remain sedated and nursed in a supine position before being weaned from the ventilator. One approach to prevent atelectasis is to apply manual hyperinflation [60] to mobilize airway secretions. The patient is disconnected from the ventilator and the lungs are inflated by using a resuscitation bag with a larger-than-normal breath at a slow inspiratory flow rate, an inspiratory pause, and a high peak expiratory flow that is achieved by the rapid release of the resuscitation bag. Paulus and colleagues [61] conducted a randomized controlled trial in 100 patients admitted to a single ICU after elective coronary artery bypass graft or cardiac valve surgery or both. In the treatment group, manual hyperinflation was performed within 30 minutes after ICU admission and every 6 hours thereafter as well as before extubation. In the control group, manual hyperinflation was performed only if there were audible sounds suggesting that there was sputum in the larger airways. The authors demonstrated that early manual hyperinflation partially prevents the reduction in FRC in the first post-operative day and was associated with decreased radiographic signs of atelectasis. These data suggest that manual hyperinflation may contribute to the recovery of collapsed lung areas after cardiac surgery.

\section{Pneumonia}

Severe pneumonia in ICU patients contributes to high mortality and morbidity rates [62]. One step necessary to help improve outcomes is to better define the degree of severity of illness in individual patients [63]. Bloos and colleagues [64] performed a multicenter observational study to test the hypothesis that serum procalcitonin (PCT) levels measured daily for 14 days can assist in identifying patients with severe pneumonia who are at high risk of poor outcome. The study included 175 patients with community-acquired pneumonia (CAP), ventilator-associated pneumonia (VAP), and hospitalacquired pneumonia. Although PCT levels were elevated at the time of enrolment (above a normal value of $0.3 \mathrm{ng} /$ $\mathrm{mL}$ ) in all groups, the maximum PCT occurred a median of 1 to 2 days after inclusion in the study. Patients with VAP had the lowest initial PCT values. Patients with 
severe CAP had the highest initial median PCT and greater disease severity and mortality than the other two types of pneumonia. Mean PCT levels were higher in non-survivors than in survivors. In that study, there was no difference in PCT values between culture-positive and culture-negative pneumonia. Both the initial and maximum PCT levels correlated with maximum Sequential Organ Failure Assessment score and were a reasonable predictor of the risk of death within 28 days. This correlation was independent of the type of pneumonia. The optimal cutoff values to predict mortality were $1.1 \mathrm{ng} / \mathrm{mL}$ for initial PCT and $7.8 \mathrm{ng} / \mathrm{mL}$ for maximum PCT. Therefore, the severity of illness may be a more important determinant of PCT levels than the type or cause of pneumonia.

\section{Abbreviations}

ARDS, acute respiratory distress syndrome; CAP, community-acquired pneumonia; CT, computed tomography; EIT, electrical impedance tomography; $\mathrm{FiO}_{2}$, fraction of inspired oxygen; $\mathrm{FRC}$, functional residual capacity; ICU, intensive care unit; $\mathrm{PaCO}$, arterial partial pressure of carbon dioxide; $\mathrm{PaO}_{2}$, arterial partial pressure of oxygen; $\mathrm{PaO}_{2} / \mathrm{FiO}_{2^{\prime}}$ arterial partial pressure of oxygen/fraction of inspired oxygen; $\mathrm{PCT}$, procalcitonin; PEEP, positive end-expiratory pressure; $\mathrm{SaO}_{2}$, saturation of oxygen in arterial blood; VAP, ventilator-associated pneumonia; VDNT, alveolar dead space; VT, tidal volume.

\section{Competing interests}

The authors declare that they have no competing interests.

\section{Authors' contributions}

All authors took part in the critical revision and interpretation of all manuscript versions.

\section{Acknowledgments}

This work was supported in part by Instituto de Salud Carlos III in Spain (PI10/0393) and the Canadian Institute for Health Research.

\section{Author details}

'CIBER de Enfermedades Respiratorias, Instituto de Salud Carlos III, Monforte de Lemos 5, 28029 Madrid, Spain. ${ }^{2}$ Multidisciplinary Organ Dysfunction Evaluation Research Network, Research Unit, Hospital Universitario Dr. Negrín, Barranco de la Ballena s/n, 4th floor south wing, 35010 Las Palmas de Gran Canaria, Spain. ${ }^{3}$ Keenan Research center at the Li Ka Shing Knowledge Institute of St. Michael's Hospital, 30 Bond Street, Toronto, ON M5B 1W8, Canada. ${ }^{4}$ Interdepartmental Division of Critical Care, Faculty of Medicine, University of Toronto, 1 Kings College Circle, Toronto, ON M5S 1A8, Canada. Intensive Care Unit, Hospital Universitario Río Hortega, Dulzaina 2, 47012 Valladolid, Spain.

Published: 10 December 2012

\section{References}

1. Rhodes A, Wort SJ, Thomas H, Collinson P, Bennett ED: Plasma DNA concentration as a predictor of mortality and sepsis in critically ill patients. Crit Care 2006, 10:R60.

2. Okkonen M, Lakkisto P, Korhonen AM, Parviai-nen I, Reinikainen M, Varpula T, Pettila V, and the FINNALI Study Group: Plasma cell-free DNA in patients needing mechanical ventilation. Crit Care 2011, 15:R196.

3. Bernard GR, Artigas A, Brigham KL, Carlet J, Falke K, Hudson L, Lamy M, Legall JR, Morris A, Spragg R: The American-European Consensus Conference on ARDS: Definitions, mechanisms, relevant outcomes, and clinical trial coordination. Am J Respir Crit Care Med 1994, 149:818-824.

4. Linko R, Okkonen M, Pettila V, Perttila J, Parviainen I, Ruokonen E, Tenhunen J, Ala-Koko T, Varpula T: Acute respiratory failure in intensive care units. FINNALI: a prospective cohort study. Intensive Care Med 2009, 35:1352-1361.

5. Arnalich F, López-Collazo E, Montiel C: Diagnostic potential of circulating cell-free DNA in patients needing mechanical ventilation: promises and challenges. Crit Care 2011, 15:187.
6. Ogura H, Tanaka H, Koh T, Fujita K, Fujimi S, Nakamori Y, Hosotsubo H, Kuwagata Y, Shimazu T, Sugimoto H: Enhanced production of endothelial microparticles with increased binding to leukocytes in patients with severe systemic inflammatory response syndrome. J Trauma 2004, 56:823-830.

7. Guervilly C, Lacroix R, Forel JM, Roch A, Camoin-Jau L, Papazian L, DignatGeorge F: High levels of circulating leukocyte microparticles are associated with better outcome in acute respiratory distress syndrome. Crit Care 2011, 15:R31.

8. Munford RS, Pugin J: Normal responses to injury prevent systemic inflammation and can be immunosuppressive. Am J Respir Crit Care Med 2001, 163:316-321.

9. Soriano AO, Jy W, Chirinos JA, Valdivia MA, Velasquez HS, Jimenez JJ, Horstman LL, Kett DH, Schein RM, Ahn YS: Levels of endothelial and platelet microparticles and their interactions with leukocytes negatively correlate with organ dysfunction and predict mortality in severe sepsis. Crit Care Med 2005, 33:2540-2546.

10. Kropski JA, Fremont RD, Calfee CS, Ware LB: Clara cell protein (CC16), a marker of lung epithelial injury, is decreased in plasma and pulmonary edema fluid from patients with acute lung injury. Chest 2009, 135:1440-1447.

11. Morales MM, Pires-Neto RC, Inforsato N, Lanças T, da Silva LF, Saldiva PH, Mauad T, Carvalho CR, Amato MB, Dolhnikoff M: Small airway remodeling in acute respiratory distress syndrome: a study in autopsy lung tissue. Crit Care 2011, $15: R 4$

12. Villar J, Blanco J, Añón JM, Santos-Bouza A, Blanch L, Ambrós A, Gandía F, Carriedo D, Mosteiro F, Basaldúa S, Fernández RL, Kacmarek RM; ALIEN Network: The ALIEN study: incidence and outcome of acute respiratory distress syndrome in the era of lung protective ventilation. Intensive Care Med 2011, 37:1932-1941.

13. Pelosi P, Rocco PR: The lung and the brain: a dangerous cross-talk. Crit Care 2011, 15:168.

14. Pustavoitau A, Stevens RD: Mechanisms of neurologic failure in critical illness. Crit Care Clin 2008, 24:1-24.

15. Quilez ME, Fuster G, Villar J, Flores C, Martí-Sistac O, Blanch L, López-Aguilar J: Injurious mechanical ventilation affects neuronal activation in ventilated rats. Crit Care 2011, 15:R124.

16. Ventilation with lower tidal volumes as compared with traditional tidal volumes for acute lung injury and the acute respiratory distress syndrome. The Acute Respiratory Distress Syndrome Network. N Engl J Med 2000, 342:1301-1308.

17. Burns KE, Adhikari NK, Slutsky AS, Guyatt GH, Villar J, Zhang H, Zhou Q, Cook DJ, Stewart TE, Meade MO: Pressure and volume limited ventilation for the ventilatory management of patients with acute lung injury: a systematic review and meta-analysis. PLOS One 2011, 6:e14623.

18. Villar J, Kacmarek RM, Pérez-Méndez L, Aguirre-Jaime A: A high positive endexpiratory pressure, low tidal volume ventilatory strategy improves outcome in persistent acute respiratory distress syndrome: a randomized, controlled trial. Crit Care Med 2006, 34:1311-1318.

19. Dellaca RL, Zannin E, Kostic P, Andersson OM, Pompilio PP, Hedenstierna G, Pedotti A, Frykholm P: Optimisation of positive end-expiratory pressure by forced oscillation technique in a lavage model of acute lung injury. Intensive Care Med 2011, 37:1021-1030.

20. Kostic P, Zannin E, Olerud ME, Pompilio PP, Hedenstierna G, Pedotti A, Larsson A, Frykholm P, Dellaca RL: Positive end-expiratory pressure optimisation with forced oscillation technique reduces ventilator induced lung injury: a controlled experimental study in pigs with saline lavage lung injury. Crit Care 2011, 15:R126.

21. Fan E, Wilcox ME, Brower RG, Stewart TE, Mehta S, Lapinsky SE, Meade MO, Ferguson ND: Recruitment maneuvers for acute lung injury: a systematic review. Am J Respir Crit Care Med 2008, 178:1156-1163.

22. Hodgson CL, Tuxen DV, Davies AR, Bailey MJ, Higgins AM, Holland AE, Keating \lrcorner , Pilcher DV, Westbrook AJ, Cooper DJ, Nichol AD: A randomised controlled trial of an open lung strategy with staircase recruitment, titrated PEEP and targeted low airway pressures in patients with acute respiratory distress syndrome. Crit Care 2011, 15:R133.

23. Yang JX, Zhang M, Liu ZH, Ba L, Gan JX, Xu SW: Detection of lung atelectasis/ consolidation by ultrasound in multiple trauma patients with mechanical ventilation. Clin Ultrasound J 2009, 1:13-16.

24. Stefanidis K, Dimipoulos S, Tripodaki ES, Vitzilaios K, Politis P, Piperopoulos P, Nanas S: Lung sonography and recruitment in patients with early acute respiratory distress syndrome: a pilot study. Crit Care 2011, 15:R185.

25. Reske AW, Reske AP, Heine T, Spieth PM, Rau A, Seiwerts M, Busse H, Gottschaldt 
U, Schreiter D, Born S, Gama de Abreu M, Josten C, Wrigge H, Amato MBP: Computed tromographic assessment of lung weights in trauma patients with early posttraumatic lung dysfunction. Crit Care 2011, 15:R71.

26. Reske AW, Reske AP, Gast HA, Seiwerts M, Beda A, Gottschaldt U, Josten C, Schreiter D, Heller N, Wrigge H, Amato MB: Extrapolation from ten sections can make CT-based quantification of lung aeration more practicable. Intensive Care Med 2010, 36:1836-1844

27. Rouby JJ, Constantin JM, Roberto A, Girardi C, Zhang M, Lu Q: Mechanical ventilation in patients with acute respiratory distress syndrome. Anesthesiology 2004, 101:228-234.

28. Dellamonica J, Lerolle N, Sargentini C, Beduneau G, Di Marco F, Mercat A, Richard JCM, Diehl JL, Mancebo J, Rouby JJ, Lu Q, Bernardin G, Brochard L: Accuracy and precision of end-expiratory lung-volume measurements by automated nitrogen washout/washin technique in patients with acute respiratory distress syndrome. Crit Care 2011, 15:R294.

29. Olegard C, Sondergaard S, Houltz E, Lundin S, Stenqvist O: Estimation of functional residual capacity at the bedside using standard monitoring equipment: a modified nitrogen washout/washin technique requiring a small change of the inspired oxygen fraction. Anesth Analg 2005, 101:206-212.

30. Tenney SM, Remmers JE: Comparative quantitative morphology of the mammalian lung: diffusing area. Nature 1963, 197:54-60.

31. Villar J, Kacmarek RM, Hedenstierna G: From ventilator-induced lung injury to physician-induced lung injury: Why the reluctance to use small tidal volumes? Acta Anaesthesiol Scand 2004, 48:267-271.

32. Gattinoni L, Pesenti A: The concept of baby lung. Intensive Care Med 2005, 31:776-784.

33. Mattingley JS, Holets SR, Oeckler RA, Stroetz RW, Buck CF, Hubmayr RD: Sizing the lung of mechanically ventilated patients. Crit Care 2011, 15:R60.

34. Han S, Martin GS, Maloney JP, Shanholtz C, Barnes KC, Murray S, Sevransky JE: Short women with severe sepsis-related acute lung injury receive lung protective ventilation less frequently: an observational cohort study. Crit Care 2011, 15:R262

35. Thille AW, Rodriguez P, Cabello B, Lellouche F, Brochard L: Patient-ventilator asynchrony during assisted mechanical ventilation. Intensive Care Med 2006, 32:1515-1522.

36. Gutierrez G, Ballarino GJ, Turkan H, Abril J, de la Cruz L, Edsall C, George B, Gutierrez $\mathrm{S}$, Jha V , Ahari J: Automatic detection of patient-ventilator asynchrony by spectral analysis of airway flow. Crit Care 2011, 15:R167.

37. Navalesi P: On the imperfect synchrony between patient and ventilator. Crit Care 2011, 15:181.

38. Amis TC, Jones HA, Hughes JM: Effect of posture on inter-regional distribution of pulmonary perfusion and VA/Q ratios in man. Respiration Physiology 1984, 56:169-182.

39. Grant CA, Pham T, Hough J, Riedel T, Stocker C, Schibler A: Measurement of ventilation and cardiac related impedance changes with electrical impedance tomography. Crit Care 2011, 15:R37.

40. Zilberberg MD, de Wit M, Pirone JR, Shorr AF: Growth in adult prolonged acute mechanical ventilation: Implications for healthcare delivery. Crit Care Med 2008, 36:1451-1455.

41. Carlucci A, Ceriana P, Prinianakis G, Fanfulla F, Colombo R, Nava S: Determinants of weaning success in patients with prolonged mechanical ventilation. Crit Care 2009, 13:R97.

42. Martin AD, Smith BK, Davenport PD, Harman E, Gonzalez-Rothi RJ, Baz M, Layon AJ, Banner MJ, Caruso L, Deoghare H, Huan TT, Gabrielli: Inspiratory muscle strength training improves weaning outcome in failure to wean patients: a randomized trial. Crit Care 2011, 15:R84.

43. Copland IB, Kavanagh BP, Engelberts D, McKerlie C, Belik J, Post M: Early changes in lung gene expression due to high tidal volume. Am J Respir Crit Care Med 2003, 168:1051-1059.

44. Faisy C, Pinto FM, Le Guen M, Naline E, Delyle SG, Sage E, Candenas ML, Devillier $P$ : Airway response to acute mechanical stress in a human bronchial model of stretch. Crit Care 2011, 15:R208.

45. Pelosi P, Tubiolo D, Mascheroni D, Vicardi P, Crotti S, Valenza F, Gattinoni L: Effects of the prone position on respiratory mechanics and gas exchange during acute lung injury. Am J Respir Crit Care Med 1998, 157:387-393.

46. Richard JC, Maggiore SM, Mancebo J, Lemaire F, Jonson B, Brochard L: Effects of vertical positiong on gas exchange and lung volumes in acute respiratory distress syndrome. Intensive Care Med 2006, 32:1623-1626.

47. Robak O, Schellongowski P, Bojic A, Laczika K, Locker GJ, Staudinger T: Shortterm effects of combining upright and prone positions in patients with ARDS: a prospective randomized study. Crit Care 2011, 15:R230.
48. Abroug F, Ouanes-Besbes L, Dachraoui F, Ouanes I, Brochard L: An updated study-level meta-analysis of randomised controlled trials on proning in ARDS and acute lung injury. Crit Care 2011, 15:R6.

49. Sud S, Sud M, Friedrich JO, Adhikari NK: Effect of mechanical ventilation in the prone position on clinical outcomes in patients with acute hypoxemic respiratory failure: a systematic review and meta-analysis. CMAJ 2008, 178:1153-1161

50. Sud S, Friedrich JO, Taccone P, Polli F, Adhikari NK, Latini R, Pesenti A, Guérin C, Mancebo J, Curley MA, Fernandez R, Chan MC, Beuret P, Voggenreiter G, Sud M, Tognoni G, Gattinoni L: Prone ventilation reduces mortality in patients with acute respiratory failure and severe hypoxemia: systematic review and meta-analysis. Intensive Care Med 2010, 36:585-599.

51. Rival G, Patry C, Floret N, Navellou JC, Belle E, Capellier G: Prone position and recruitment manoeuvre: the combined effect improves oxygenation. Crit Care 2011, 15:R125

52. Cakar N, der Kloot TV, Youngblood M, Adams A, Nahum A: Oxygenation response to a recruitment maneuver during supine and prone positions in an oleic acid-induced lung injury model. Am J Respir Crit Care Med 2000, 161:1949-1956.

53. Pelosi P, Bottino N, Chiumello D, Caironi P, Panigada M, Gamberoni C, Colombo G, Bigatello LM, Gattinoni L: Sigh in supine and prone position during acute respiratory distress syndrome. Am J Respir Crit Care Med 2003, 167:521-527.

54. Lim CM, Jung H, Koh Y, Lee JS, Shim TS, Lee SD, Kim WS, Kim DS, Kim WD: Effect of alveolar recruitment maneuver in early acute respiratory distress syndrome according to antiderecruitment strategy, etiological category of diffuse lung injury, and body position of the patient. Crit Care Med 2003, 31:411-418.

55. Oczenski W, Hörmann C, Keller C, Lorenzl N, Kepka A, Schwarz S, Fitzgerald RD: Recruitment maneuvers during prone positioning in patients with acute respiratory distress síndrome. Crit Care Med 2005, 33:54-61.

56. Charron C, Repesse X, Bouferrache K, Bodson L, Castro S, Page B, Jardin F, Vieillard-Baron $\mathrm{A}: \mathrm{PaCO}_{2}$ and alveolar dead space are more relevant than $\mathrm{PaO}_{2} / \mathrm{FiO}_{2}$ ratio in monitoring the respiratory response to prone position in ARDS patients: a physiological study. Crit Care 2011, 15:R175.

57. Gattinoni L, Vagginelli F, Carlesso E, Taccone P, Conte V, Chiumello D, Valenza F, Caironi P, Pesenti A; Prone-Supine Study Group: Decrease in $\mathrm{PaCO} 2$ with prone position is predictive of improved outcome in acute respiratory distress síndrome. Crit Care Med 2003, 31:2727-2733.

58. Siddiki H, Kojicic M, Yimaz, Thompson TB, Humayr RD, Gajic O: Bedside quantification of dead-space fraction using routine clinical data in patients with acute lung injury: secondary analysis of two prospective trials. Crit Care 2010, 14:R141.

59. Shapira N, Zabatino SM, Ahmed S, Ahmed S, Murphy DM, Sullivan D, Lemole GM: Determinants of pulmonary function in patients undergoing coronary bypass operations. Ann Thorac Surg 1990, 50:268-273.

60. Paulus F, Binnekade JM, Middelhoek P, Schultz MJ, Vroom MB: Manual hyperinflation of intubated and mechanically ventilated patients in Dutch intensive care units-a survey into current practice and knowledge. Intensive Crit Care Nurs 2009, 25:199-207.

61. Paulus F, Veelo DP, de Nijs SB, Beenen LFM, Bresser P, de Mol BAJM, Binnekade $J M$, Schultz MJ: Manual hyperinflation partly prevents reductions of functional residual capacity in cardiac surgical patients -randomized controlled trial. Crit Care 2011, 15:R187.

62. De Pascale G, Bello G, Tumbarello M, Antonelli M: Severe pneumonia in intensive care. Curr Opin Pulm Med 2012, 18:213-221.

63. Brown SM, Dean NC: Defining and predicting severe community-acquired pneumonia. Curr Opin Infect Dis 2010, 23:158-164.

64. Bloos F, Marshall JC, Dellinger RP, Vincent JL, Gutierrez G, Rivers E, Balk RA, Laterre $P F$, Angus DC, Reinhart K, Brunkhorst FM: Multinational, observational study of procalcitonin in ICU patients with pneumonia requiring mechanical ventilation: a multicenter observational study. Crit Care 2011, 15:R88.

\section{doi:10.1186/cc11422}

Cite this article as: Villar J, et al:: Year in review 2011: Critical Care -

respirology. Critical Care 2012, 16:243. 